\title{
Reviews on Current Carbon Emission Reduction Technologies and Projects and their Feasibilities on Ships
}

\author{
Haibin Wang ${ }^{1 *}$, Peilin Zhou ${ }^{1,2}$ and Zhongcheng Wang ${ }^{2}$ \\ 1. Department of Naval Architecture, Ocean and Marine Engineering, University of Strathclyde, Glasgow G4 OLZ, UK \\ 2. Shanghai Maritime University, Merchant Marine College, Shanghai 201306, China
}

\begin{abstract}
Concern about global climate change is growing, and many projects and researchers are committed to reducing greenhouse gases from all possible sources. International Maritime Organization (IMO) has set a target of $20 \% \mathrm{CO}_{2}$ reduction from shipping by 2020 and also presented a series of carbon emission reduction methods, which are known as Energy Efficiency Design Index (EEDI) and Energy Efficiency Operation Indicator (EEOI). Reviews on carbon emission reduction from all industries indicate that, Carbon Capture and Storage (CCS) is an excellent solution to global warming. In this paper, a comprehensive literature review of EEDI and EEOI and $\mathrm{CCS}$ is conducted and involves reviewing current policies, introducing common technologies, and considering their feasibilities for marine activities, mainly shipping. Current projects are also presented in this paper, thereby illustrating that carbon emission reduction has been the subject of attention from all over the world. Two case ship studies indicate the economic feasibility of carbon emission reduction and provide a guide for CCS system application and practical installation on ships.

Keywords: marine environment control, carbon reduction technologies, EEDI, EEOI, CCS, chemical absorption
\end{abstract}

Article ID: 1671-9433(2017)02-0000-08

\section{Introduction}

Climate change is caused by massive greenhouse gases (GHG), including water vapor, carbon dioxide $\left(\mathrm{CO}_{2}\right)$, methane, nitrous oxide, and tropospheric ozone, generated from human activities and emitted into the atmosphere (Houghton, 2004). The greenhouse effects caused by GHG can help to prevent massive heat from radiating to outer space, thereby ensuring that the earth is kept warm enough for creatures to survive in the cold night without sunlight (National Geographic, 2016).

IMO aims to reduce $\mathrm{CO}_{2}$ emission from marine activities by $14 \%$ by 2020 . A report from IMO estimated that international shipping contributed approximately $2.2 \%$ to the global $\mathrm{CO}_{2}$ emissions in 2012 (IMO, 2014). However, shipping is still the most efficient transportation method with minimal $\mathrm{CO}_{2}$ emission. IMO has introduced regulations to increase the energy efficiency of ships so that fewer emissions can be achieved for the same working load. However, further emission control is always required to slow down the pace of

Received date: 06-May-2016 Accepted date: 02-Mar-2017

*Corresponding author Email: haibin.wang.100@strath.ac.uk global warming. Carbon Capture and Storage (CCS) is a technique where $\mathrm{CO}_{2}$ from fossil fuels is captured and transported to a storage site. Several active projects apply CCS onshore for power plants and industrial processes (Global CCS Institute, 2012). The inspiration of our research is these onshore applications as they could reduce $\mathrm{CO}_{2}$ emission considerably. Unfortunately, these methods cannot be installed on ships directly because of limitations such as power demand, constraint volume, and stability. With all these considerations, this research aims to find a reasonable solution for ship $\mathrm{CO}_{2}$ emission control. Referring to Lloyd's List, the European Union (EU) aims to reduce GHG emission by at least $20 \%$ by 2020 compared with 1990 levels. The US has also made efforts to reduce GHG emission, establishing a tough target. A $20 \%$ reduction of $\mathrm{CO}_{2}$ emission from ships was also set as a global target to be achieved in 2020 by the United Nations (International Chamber of Shipping, 2014). Apparently, GHG emission reduction is becoming a main stream of environment protection. These reviews indicate that the significance of actions and policies for $\mathrm{CO}_{2}$ reduction is clear, and methods are available to help achieve it. 450 Scenario says global temperatures have to be stabilized within $2{ }^{\circ} \mathrm{C}$ compared with pre-industrial levels. According to the IPCC Assessment Report 4, $\mathrm{CO}_{2}$ emissions need to decline before 2015 and should be further reduced to less than $50 \%$ of today's emissions by 2050 . All these requirements indicate the urgency of $\mathrm{CO}_{2}$ emission reduction.

Policies for GHG reduction are necessary. Thus, we need to carefully plan strategies for emission reduction. This issue is apparently the most practical question, but addressing it requires a feasible solution. $\mathrm{CO}_{2}$ emissions generally come from energy supply, industry, forestry, agriculture, transportation, residential and commercial building, and wastes.

\section{Literature review}

\subsection{Current $\mathrm{CO}_{2}$ situation}

Over centuries of fossil fuel consumption, the $\mathrm{CO}_{2}$ concentration in the atmosphere has increased by $100 \mathrm{ppm}$ 
according to a report from Metz et al. (2007). The increase in $\mathrm{CO}_{2}$ in the atmosphere, as a nature of GHG, directly results in global warming and puts all creatures on the planet at risk. This situation is critical and a solution is required to ensure global sustainability. This section will elaborate the current situation of $\mathrm{CO}_{2}$ emission from different angles, and a prediction of future conditions will be presented.

\section{2 $\mathrm{CO}_{2}$ emissions}

The first pie chart in Fig. 1 indicates the amount of different emission gases in percentage. The pie chart, which is based on an IPCC report, illustrates that $\mathrm{CO}_{2}$ emissions are greate than any other gases as they constitute $77 \%$ of the total GHG emissions. In detail, $74 \%$ of $\mathrm{CO}_{2}$ emissions are attributed to fossil fuel combustion, and only $22 \%$ is due to deforestation and decayed biomass. Hence, more consideration of $\mathrm{CO}_{2}$ emission from fuel utilization is necessary to mitigate climate change.

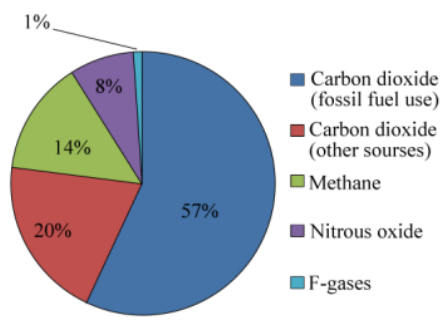

(a) GHG emissions

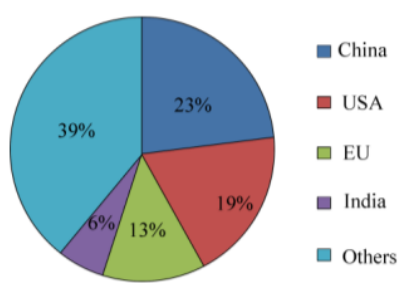

(b) Emission by countries

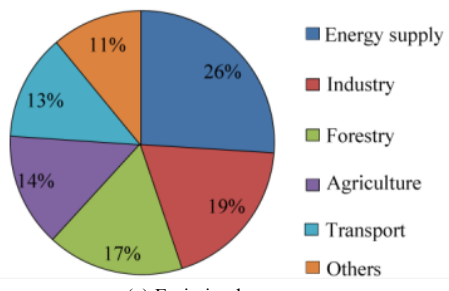

(c) Emission by source

Fig. 1 GHG emissions by gas type, countries, and sources

The second pie chart in Fig. 1 indicates that the increase in $\mathrm{CO}_{2}$ content in the atmosphere does not come from only a single country or community. Rather, global emission is an international problem because the global economy is growing rapidly and all the countries rely on one another. Thus, cooperating to address the problem is necessary. The chart shows that China has the highest $\mathrm{CO}_{2}$ emissions, followed by the US and the EU. These countries should be aware of the serious effects of GHG emission and should take action as soon as possible. In fact, all countries should carry out a suitable and reasonable policy for GHG control based on their specific situations.

The Second IMO GHG Study 2012 indicates that shipping emitted 1046 million tons of $\mathrm{CO}_{2}$ in 2007 or approximately $3.3 \%$ of the global emissions. The marine engineering field contributed a relatively small quantity, but marine engineering workers should contribute to GHG emission reduction efforts as well. The IMO has already set regulations and proposed measures for marine emission reduction to ensure a more sustainable environment. IMO (2014) indicated that approximately 938 million tons of $\mathrm{CO}_{2}$ emissions come from shipping, and 796 million tons were contributed by international shipping in 2012 .

\subsection{Prediction}

Climate change continues to be a critical issue because $\mathrm{CO}_{2}$ emissions are growing. Fig. 2 presents a chart with a trend line of global $\mathrm{CO}_{2}$ emissions from fossil fuels from 2000 to 2013 according to data from Carbon Dioxide Information Analysis Centre (Boden et al., 2010). The tendency illustrates the rapid increase in emissions, and this increase can be predicted easily. This plot shows that despite a slight decline in 2009, emissions continue to increase because of a lack of related policies and actions. Global warming has already influenced the environment and climate all over the world Mitigation the greenhouse effect is necessary, and carbon trade should be implemented as soon as possible.

As indicated previously, the large amount of $\mathrm{CO}_{2}$ emissions should be attributed to all nations, and all emission sources should be seriously considered as well. Reducing $\mathrm{CO}_{2}$ emissions in every field is a key to climate change mitigation. CCS is a way to reduce emissions from fossil fuel burning (Stern, 2011).

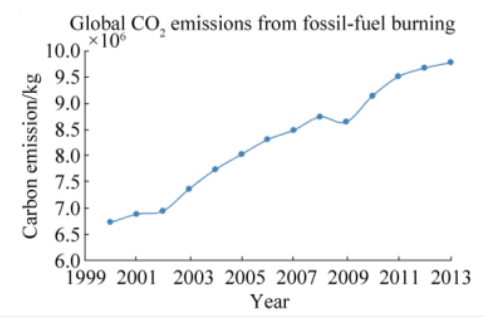

Fig. 2 Tendency of $\mathrm{CO}_{2}$ emissions from 2000 to 2013

\section{EEDI and EEOI}

3.1 What are EEDI and EEOI?

This section introduces the GHG emission control methods 
proposed by IMO. IMO regulation aims to reduce $\mathrm{CO}_{2}$ emission by increasing the energy efficiency of marine activities. The amount of $\mathrm{CO}_{2}$ from fuels is fixed and can be calculated by applying conversion factors of fuels. For example, $\mathrm{CO}_{2}$ emission from high-sulfur fuel oils is 3.075 times that of fuel. The conversion factors of several fuels are listed in Table 1 (MEPC, 2010). Therefore, if energy efficiency is increased, then the actual work performed in a fixed time will grow with the same $\mathrm{CO}_{2}$ emission.

Table 1 Conversion factors for common fuels

\begin{tabular}{cc}
\hline Fuel type & $\begin{array}{c}\text { Conversion factor } \\
\text { (ton } \mathrm{CO}_{2} / \text { ton fuel) }\end{array}$ \\
\hline Marine diesel and gas oils & 3.082 \\
Low-sulfur fuel oils & 3.075 \\
High-sulfur fuel oils & 3.021 \\
Liquefied natural gas & 2.750 \\
Liquid petroleum gas: propane & 3.000 \\
Liquid petroleum gas: butane & 3.030 \\
\hline
\end{tabular}

To improve the energy efficiency of international shipping, new regulations entered into force on January 01, 2013. IMO adopted a series of amendments and added them to the International Convention for the Prevention of Pollution from Ships in July 2011 (IMO, 2011). A new chapter was added to the MARPOL Annex VI for mandatory regulations for different types of ships, such as EEDI for new ships, EEOI for existing ships, and Ship Energy Efficiency Plan (SEEMP) for all ships. These regulations apply to all ships with 400 gross tonnages and above. For these energy efficiency improvement methods, their calculations basically come from the ratio between $\mathrm{CO}_{2}$ emissions and transport work. For example, the $\mathrm{CO}_{2}$ emission for a new vessel (applying EEDI) is indirectly obtained by multiplying the power output and the fuel consumption of all engines with fuel carbon factors. The transport work is derived by multiplying capacity with the reference speed of the selected vessel. The ratio between $\mathrm{CO}_{2}$ emission and transport work presents the EEDI of the vessel. A comparison between the designed EEDI with the target value in IMO regulations indicates whether further $\mathrm{CO}_{2}$ emission reduction is required.

The measures mainly involve methods that increase energy efficiency through improved designs and effective operations. Greater GHG emission reduction is achieved compared with that in the second and the third IMO GHG studies. EEDI for new buildings and EEOI and SEEMP for all ships are predominant methods that can be performed in the ship design and operation stages. Reducing GHG emissions by reducing fuel consumption is reasonable. Fuel cost and $\mathrm{CO}_{2}$ emissions are both reduced. Most emission reduction applications are already utilized on ships because of shipyard and customer requirements.

\subsection{Available technologies and current projects}

Many different technologies focus on different areas of ships to improve energy efficiency, from the main machineries to the ship hull, from the design stage to the operation stage. The technologies are mature for onboard applications. Thus, two projects will be introduced in this summary.

MAN Diesel \& Turbo (2014) tested the influence of the parameters of the propeller on energy efficiency. Three case studies were carried out on three vessels. Propeller diameter and blade numbers were tested to determine how they affect fuel consumption. The optimization of propeller parameters can reduce $\mathrm{CO}_{2}$ emission by $30 \%$ for most container ships with MAN S80 and S90 main engines.

Shao and his colleagues from University of Strathclyde focused on route optimization during the operation stage (Shao et al., 2012). This project aims to determine the optimal transportation route for ships with primary focus on weather routing. The project developed a novel 3D dynamic programing method using an empirical formula for speed calculation in various weather conditions and IMO guideline for safety voyage. One case study was carried out to illustrate the application of this weather routing program. Findings indicate that with the help of this program, an optimized route can be determined and minimum fuel consumption can be obtained considering different weather conditions.

\section{CCS technologies}

\subsection{What is CCS?}

CCS refers to a series of techniques applied to emission sources, such as power plants and industrial processes, to separate $\mathrm{CO}_{2}$ from fossil fuel or flue gas, transport it using pipelines or ships, and store it underground or in the ocean (Global CCS Institute, 2012). CCS is an effective way to mitigate or even eliminate climate change. By the end of the 2012, 14 active CCS industrial projects on shore exist according to the Global CCS Institute. The Boundary Dam Integrated Carbon Capture and Sequestration Demonstration Project is an active CCS project that was launched in 2014 in Canada. The project focuses on a power station. An aminebased post-combustion capture method is applied for capture. The $\mathrm{CO}_{2}$ is transported through a pipeline, and Enhanced Oil Recovery (EOR) is selected for $\mathrm{CO}_{2}$ storage (SaskPower, 2014). The Gorgon Carbon Dioxide Injection Project is an Australian project that was ready for operation in 2016. The target is natural gas processing, and this CCS project applies pre-combustion capture (natural gas processing), pipeline, and EOR (Gorgon Australia, 2015). FutureGen 2.0 Project is an under defined CCS project and will apply oxy-fuel combustion capture on power stations in the US Compression will be applied for separation. A pipeline and dedicated geological storage will be utilized for $\mathrm{CO}_{2}$ transportation and storage (U.S. Department of Energy, 2013).

This review focuses mainly on CCS because this paper aims to contribute to research on capture technologies and developments for marine vessels.

\subsection{CCS technologies}

Commented [p1]: Please list it in "References" or delete it.
Commented [HW2R1]: added


Capturing carbon from fossil fuels ensures that $\mathrm{GHG}$ (especially $\mathrm{CO}_{2}$ ) will not be emitted to the atmosphere. Without GHG emission, climate change (global warming) will be alleviated and eventually prevented. Three main methods are widely used and currently applied on power plants: pre-combustion, oxy-fuel, and post-combustion capture. These methods are based on different principles, and thus, their applications may vary. The following sections will introduce these capture methods in detail so that the selection of a capture method for marine application can be based on the characteristics of different methods.

\subsubsection{Pre-combustion capture}

The first capture method is pre-combustion capture. Its main principle method is to remove $\mathrm{CO}_{2}$ from the fossil fuel prior to combusting it.

As shown in the first schematic diagram of Fig. 3, the fossil fuel for power plants is reformed with steam, and a mixture gas of $\mathrm{CO}_{2}$ and $\mathrm{H}_{2}$ (hydrogen) is produced. Two reactions occur: steam-reforming reactions generate synthesis gas (a mixture of $\mathrm{CO}$ and $\mathrm{H}_{2}$, also known as syngas) and water-gas shift reaction transfer $\mathrm{CO}$ to $\mathrm{CO}_{2}$. Both reactions generate $\mathrm{H}_{2}$, which can be used as fuel by a hydrogen gas turbine. The final products are $\mathrm{CO}_{2}$ and $\mathrm{H}_{2}$. The $\mathrm{CO}_{2}$ can be captured through suitable methods, and $\mathrm{H}_{2}$ is separated as fuel for power plant, which will not generate any $\mathrm{CO}_{2}$. The popular methods used for $\mathrm{CO}_{2}$ capture are chemical absorption with absorbent or condensation method.

This method is applicable to integrated gasification or natural gas combined cycle power stations. It is a highefficiency, low-risk technique, and it can capture $90 \%-95 \%$ of $\mathrm{CO}_{2}$ from fuel oil. However, installation on the plant requires coupling with a chemical plant for reforming and capture, thereby requiring a large initial investment for the design, building, and integration of the system. The gas turbine with hydrogen fuel is also a major problem because of low efficiency and high nitrogen dioxide emission, especially $\mathrm{NO}_{2}$.

\subsubsection{Oxy-fuel capture}

Oxy-fuel capture combusts fossil fuel within pure oxygen rather than within air. The oxygen is separated first from air by separation devices. After the combustion, the emission gases have a high concentration of $\mathrm{CO}_{2}(90 \%)$ because of a relatively complete combustion and few impurities in oxygen. Hence, $\mathrm{CO}_{2}$ separation under this condition is easy. As shown in the second flowchart in Fig. 3, after combustion processes, only condensation or compression is required to separate $\mathrm{CO}_{2}$ and water.

Regardless of the energy consumed, potentially $100 \%$ of $\mathrm{CO}_{2}$ can be captured with this method. The emission of other gases, such as $\mathrm{NO}_{\mathrm{x}}$ and $\mathrm{SO}_{\mathrm{x}}$, are directly reduced because of complete combustion. The oxy-fuel capture system can be retrofitted to existing power plants as it does not affect the power plant significantly. A significant issue for existing plants is that the combustion temperature is higher than it used to be with high oxygen concentration. A higher material quality of combustion chambers may be required, and an excessively high power penalty is a major drawback of the method. Currently, only a few power plants apply this method because the method is still in the research and development stage.

\subsubsection{Post-combustion capture}

This method captures $\mathrm{CO}_{2}$ from exhaust gases after fossil fuel combustion. Usually, power stations that apply this carbon capture method are retrofitted with an exhaust gas treatment system, as illustrated in the third chart in Fig. 3. Chemical sorbent is typically used to absorb $\mathrm{CO}_{2}$ and then heat is applied or the pressure is increased to release $\mathrm{CO}_{2}$ from the absorbent for further storage. Nowadays, amine and quicklime are used as sorbent because they ensure a high absorption rate and release gas while applying heat and pressure. Other $\mathrm{CO}_{2}$ separation methods are currently being researched, such as the use of active carbon and membrane.

As the system is based on processes of exhaust gas treatments, retrofitting is the easiest among three methods. This method introduces the least changes on target plants and is also the most mature method, as it has been used for at least half a century. Despite these merits, retrofitting also needs to be improved in terms of reducing running cost, such as through recycling and replacement of absolvent. Moreover, its use in large-scale power plants is limited and needs further research and development.

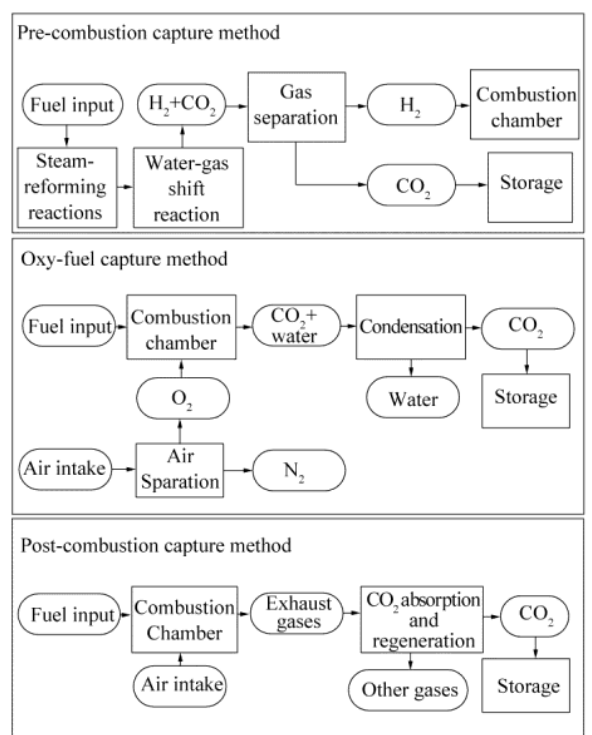

Fig. 3 Schematics of general carbon capture methods

Table 2 shows the currently available technologies and those under development for all three mentioned methods. Basically, these capture technologies can be applied on all the 
capture methods.

Usually, the captured $\mathrm{CO}_{2}$ will be transported in either gaseous or liquid form. Currently, liquefied $\mathrm{CO}_{2}$ transportation is more popular because $\mathrm{CO}_{2}$ in dense phase has a high density and low viscosity. $\mathrm{CO}_{2}$ is usually compressed with multistage compressions and into dense phase. Under these conditions, low storage volumes and low transportation pressure are required, thereby making transportation in both pipeline and ships greatly convenient and efficient.

\subsection{Feasibilities for ships}

Generally, many capture techniques are available for all the three capture methods but with different conditions and efficiencies. These methods for industrial uses and power plants aim to capture $\mathrm{CO}_{2}$ from fossil fuels and transport and store it in suitable and profitable locations, such as active or depleted oil fields for EOR. Sometimes, $\mathrm{CO}_{2}$ is stored in $\mathrm{CO}_{2}$ lakes in the ocean. Some projects trap $\mathrm{CO}_{2}$ in underground saline aquifer layers. As mentioned in the previous section, $\mathrm{CO}_{2}$ can be transported in either the gaseous phase or the dense phase. Transition of $\mathrm{CO}_{2}$ into dense phase is popular not only for onshore transportation but also for ship applications. In gaseous form, $\mathrm{CO}_{2}$ occupies a considerable volume. These onshore capture methods apply a compression process for convenient and efficient transportation and storage. However, if these methods are applied on ships mechanically, then serious problems arise, such as power penalties, space requirements for storage, and safety issues from liquid cargo.

Table 2 Carbon capture methods and technologies

\begin{tabular}{cccccc}
\hline Separation task & Capture techniques & Solvents & Membranes & Solid sorbents & Cryogenic \\
\hline Pre-combustion Capture & $\mathrm{CO}_{2} / \mathrm{H}_{2}$ & $\begin{array}{c}\text { Physical solvents } \\
\text { Chemical solvents }\end{array}$ & Polymeric & $\begin{array}{c}\text { Zeolites } \\
\text { Activated carbon } \\
\text { Alumina }\end{array}$ & Liquefaction \\
\hline Oxy-fuel combustion Capture & $\mathrm{O}_{2} / \mathrm{N}_{2}$ & N.A. & Polymeric & $\begin{array}{c}\text { Zeolites } \\
\text { Activated carbon }\end{array}$ & Distillation \\
\hline Post-combustion Capture & $\mathrm{CO}_{2} / \mathrm{N}_{2}$ & Chemical solvents & Polymeric & $\begin{array}{c}\text { Zeolites } \\
\text { Activated carbon }\end{array}$ & Liquefaction \\
\hline
\end{tabular}

\subsubsection{Pre-combustion capture}

As mentioned previously, this method is not available for existing ships because too many changes are required to install the capture system. Changes such as reaction tank installations, engine type change, and extra exhaust pollution treatment are major challenges that may exceed the capabilities of ship owners. Two types of reaction tanks for transforming fossil fuel into hydrogen fuel require significant cost. The engine fuel will become hydrogen fuel, which means changing engine type entirely. Furthermore, the high temperature combustion of hydrogen generates more $\mathrm{NO}_{\mathrm{x}}$ emissions, which is a common result of hydrogen fuel gas turbines. These three points easily undermine ship owners' confidence in this capture method. Hence, this method is not yet ready for existing ships.

Fortunately, this method is a good choice for new ships. Tanks can be designed and positioned properly. The main engines and emission control systems could be selected at the design stage as well. These problems are solved, and many other merits are identified. $\mathrm{CO}_{2}$ concentration after separation and before capture is relatively high, which will increase the efficiency of capture process. The pressure of $\mathrm{CO}_{2}$ gas (typically $2-7 \mathrm{MPa}$ ) is suitable for storage. In this way, the efficiency of capture is relatively high

This method is not yet mature for ships and will not be selected in this paper. However, if hydrogen fuel engines are well designed and widely applied, then this method can feasibly produce hydrogen from fossil fuel on board in a $\mathrm{CO}_{2}$ emission-free manner.

\subsubsection{Oxy-fuel combustion capture}

Oxy-fuel combustion capture involves burning fuel in high-purity oxygen instead of air. The system could be retrofitted to the engine as air separation equipment should be placed in front of the air inlet. The air separation system is based on industrial oxygen production technologies such as air separation comprise cryogenic distillation, adsorption using multi-bed pressure swing units, and polymeric membranes. A flue gas circle mixes the flue gas with the input oxygen to achieve a high combustion temperature. Furthermore, the emission conditions are different from original ones and should be considered a result of pure oxygen feeding. The cost of this method comes primarily from the power required of the air separation and feeding system. The selection and improvement of these aspects will optimize the running cost.

Combustion with pure oxygen has positive effects, but this method is not ready for commercial use and is currently used in the metal smelting industry only. Many factors should be considered when applying oxy-fuel combustion in CCS. If installed on ships, then the new equipment should be installed in restricted sites, which may pose a serious problem for ship owners.

\subsubsection{Post-combustion capture}

As a relatively mature method, post-combustion capture is more widely used in power plants and industrial processes than the other two methods. Its widespread use is also due to the fact that direct firing of fossil fuel in air is the most economical method in large-scale processes. A retrofitted 
capture system can also be coupled with the existing system similar to the oxy-fuel combustion system. The difference is that the post-combustion capture system is installed after the combustion. The system could be coupled with the exhaust gas emission system of engines directly where varies of separation system can be applied to capture $\mathrm{CO}_{2}$. The main cost is the investment in the capture system but is lower than that of the other two methods. Absorption processes based on chemical solutions are currently preferred for postcombustion $\mathrm{CO}_{2}$ capture and require an absorbent for absorption and heat for absorbent regeneration.

$\mathrm{CO}_{2}$ liquefaction or compression is also widely used for onshore applications, which require considerable energy and increase energy demand because a high amount of power is required for compression while changing the gas phase to the dense liquid phase. Space requirements are high because new equipment and storage tanks need to be installed. The space in ships is limited. Thus, space for CCS should be small so that the system will not occupy cargo space. Otherwise, $\mathrm{CO}_{2}$ storage on ships will severely affect ship transportation. Another problem of $\mathrm{CO}_{2}$ compression is that the state of $\mathrm{CO}_{2}$ is complicated, and any change in temperature or pressure may change the density and volume and even may result in a phase change (Barthelemy et al., 2010). While the liquid $\mathrm{CO}_{2}$ turns into gas, a large pressure occurs and may introduce a risk of leakage or even explosion. Given the strict storage conditions of $\mathrm{CO}_{2}$ liquefaction, storage tank material requirements are high. As the ship operates, $\mathrm{CO}_{2}$ will be captured and stored as liquid in tanks, and a sloshing effect may occur in the storage tanks, thereby affecting the stability of the ship and seriously influencing shipping performance.

\subsection{Current projects}

An obvious drawback for carbon capture on ships is that a large amount of exhaust gases are generated and need to be separated, which may need a large-scale absorption system. Another disadvantage is the low concentration and purity of $\mathrm{CO}_{2}$ in exhaust gas because many other gases are present in the exhaust gases and need to be separated from $\mathrm{CO}_{2}$. Some gases such as $\mathrm{SO}_{2}$ and $\mathrm{SO}_{3}$ may affect and degrade the absorption solution. These gases are acid gas pollutants that can react with alkaline solutions. Usually, a scrubber is installed for flue gas desulfurization, which is a common $\mathrm{SO}_{\mathrm{x}}$ treatment method. However, the degradation of absorbent is still unavoidable because achieving $100 \%$ the treatment efficiency is difficult.

From the point of $\mathrm{CO}_{2}$ capture, all these three methods use the same techniques, but the capture rates are slightly different. The objective is to install CCS on ships, and thus, installation constraints should be carefully considered.

Although the above mentioned IMO $\mathrm{CO}_{2}$ emission reduction target could be achieved through energy efficiency improvement methods (EEDI, EEOI, and SEEMP), CCS is still a reasonable and feasible way to mitigate climate change. CCS methods aim to provide a suitable emission control method and an optional way to enhance the carbon reduction. Currently, CCS is relatively more mature for power plants and industry processes than for maritime applications. Only a few CCS applications for ships exist. In Europe, the Process Systems Enterprise (PSE) is working with DNV GL on an onship CCS to reduce marine GHG emissions and meet regulations (DNV GL and PSE, 2013). Amine absorption, pressure-swing adsorption, heat- integrated distillation, and membrane processes are being considered. A DNV report has indicated that, with $\mathrm{CCS}$ on ship, $\mathrm{CO}_{2}$ emission can be reduced by $65 \%$.

The Department of Naval Architecture, Ocean, and Marine Engineering in Strathclyde University has worked on a postcombustion CCS method for ships. The project aims to reduce $20 \%$ of $\mathrm{CO}_{2}$ emissions from ships in accordance with IMO regulations. A chemical-based absorption method was selected for separating $\mathrm{CO}_{2}$ emission from exhaust gas and storing it in a stable compound. The final products will be traded to the building industry to reduce application costs (Zhou \& Wang, 2014; Wang et al., 2016). The following sections present two case studies from this research project.

Although CCS is a suitable and reasonable choice, few projects and studies on developing CCS for marine purposes have been conducted. More research is needed for the development of maritime CCS.

An advantage of international shipping over other transportation options is its density. Most cargos can be transported by many different types of ships. Container ships, bulk carriers, and tanker ships are typical vessels that are mostly used for international transportation, and they also contribute most of the $\mathrm{CO}_{2}$ emissions according to the IMO (2014). Fig. 4 shows the $\mathrm{CO}_{2}$ emissions of all vessel types for international shipping. Among the three vessel types, container ship and bulk carrier contribute the most $\mathrm{CO}_{2}$ emissions at approximately 205 and 166 million tons, respectively, and are therefore the focus of the case studies.

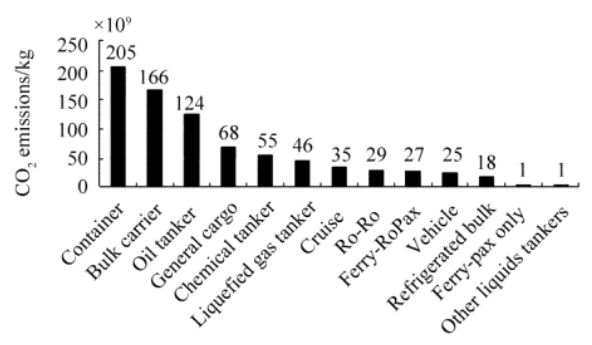

Fig. $4 \mathrm{CO}_{2}$ emissions from international shipping by ship type (2012)

4.4.1 Case ship study 1: economic feasibility

The project conducted in University of Strathclyde involved the application of an alkaline solution to absorb the $\mathrm{CO}_{2}$ emission of a bulk carrier, and the $\mathrm{CO}_{2}$ was stored in a stable chemical compound $\left(\mathrm{CaCO}_{3}\right)$. The product can be sold upon reaching the destination. The principles of the process are as follows:

$\mathrm{CO}_{2}(\mathrm{~g})+2 \mathrm{NaOH}=\mathrm{Na}_{2} \mathrm{CO}_{3}+\mathrm{H}_{2} \mathrm{O}$ 


\section{$\mathrm{Na}_{2} \mathrm{CO}_{3}+\mathrm{CaO}+\mathrm{H}_{2} \mathrm{O}=\mathrm{CaCO}_{3}(\mathrm{~s})+2 \mathrm{NaOH}$}

Table 3 presents the costs and profits of CPCS in comparison with the conventional liquefied $\mathrm{CO}_{2}$ storage method as indicated by a cost analysis of the above case ship.

If the $\mathrm{CaCO}_{3}$ was sold at the destination, then applying CPCS can earn a profit of $\$ 35981.07$ while capturing 20\% $\mathrm{CO}_{2}$ emissions from engine exhaust.

The operation cost and profit made from the liquefaction method are listed in the Table 3. No chemical substances are involved in liquefaction, and thus, no purchase costs for chemical substances exist. However, the energy cost due to $\mathrm{CO}_{2}$ liquefaction processes is considerable, as shown by the liquefaction cost in the table. Freight reduction is due to liquefied $\mathrm{CO}_{2}$ storage. The profits are made from saving carbon credits and selling $\mathrm{CO}_{2}$ for EOR.

\section{Table 3 Cost and profit comparison}

$\$$

\begin{tabular}{cccc}
\hline \multicolumn{2}{c}{ Costs per voyage } & CPCS & Liquefaction \\
\hline \multirow{4}{*}{$\begin{array}{c}\text { Operation } \\
\text { costs }\end{array}$} & Capture cost & 18073 & 18073 \\
& Chemical cost & 27347 & - \\
& Liquefaction cost & - & $21021^{\mathrm{b}}$ \\
& Freight reduction & 15502 & 9932 \\
\hline \multirow{3}{*}{ Profits } & Carbon credits & $-11300^{\mathrm{a}}$ & -11300 \\
& $\mathrm{CaCO}_{3}$ & -85603 & - \\
& $\mathrm{CO}_{2}$ & - & $-18833^{\mathrm{c}}$ \\
\hline \multicolumn{2}{c}{ Total costs } & -35981 & 6758 \\
\hline
\end{tabular}

a: Negative sign means earning profits; b: Wischnewski (2006); Glenn
(1998); c: Melzer and Midland (2012).

4.4.2 Case ship study 2: practical installation

Before designing the dimensions of different tanks, the selected container ship is modeled first. The selected ship is a $6300 \mathrm{TEU}$ (twenty-foot equivalent unit) class container carrier. The details of this vessel and the engine specification are listed in Tables 4 and 5, respectively.

Table 4 Container ship details

\begin{tabular}{cc}
\hline$L_{\mathrm{OA}} / \mathrm{m}$ & 304 \\
$L_{\mathrm{BP}} / \mathrm{m}$ & 292 \\
Breadth $/ \mathrm{m}$ & 40 \\
Depth $/ \mathrm{m}$ & 24.2 \\
Draught $/ \mathrm{m}$ & 12 \\
Voyage duration $/ \mathrm{d}$ & 16 \\
Shipping capacity/TEU & 6300 \\
\hline
\end{tabular}

Table 5 Main engine specification

\begin{tabular}{cc}
\hline Engine type & B\&M 10K98MC-C \\
$\mathrm{MCR} / \mathrm{kW}$ & 57059 \\
$\mathrm{SFOC} /(\mathrm{g} / \mathrm{kWh})$ & 171 \\
Fuel carbon factor & 3.021 \\
\hline
\end{tabular}

Considering the dimensions of all tanks and assigned containers, a CAD drawing is derived. In Fig. 5, 385 designed containers for $\mathrm{CaO}$ and $\mathrm{CaCO}_{3}$ are assigned to the No. 7 hold, and an arrangement example in this figure contains the operation site at the bottom and the transportation routes: blue: storage tanks (containers); yellow: storage tank working place; green: absorption, solidification, and separation processes working place; gray: transportation routes.

Fig. 6 presents the locations of all tanks before storage tanks. These systems include a bypass system from funnel and a pipeline that transports the exhausted gas into absorption reaction tank. The fitting pipeline is in light blue color. The green color represents the absorption reaction tanks, and the pink and red ones are the precipitation tanks. The centrifuge separation system is denoted in dark blue, and the yellow ones indicate transportation. All the gray compartments with grids indicate the ship hull.

Exhaust gases are bypassed and fed into the absorption system, and $\mathrm{CO}_{2}$ is trapped in the solution. The $\mathrm{CO}_{2}$-rich solution is transported to the precipitation tank, and $\mathrm{CO}_{2}$ is solidified into $\mathrm{CaCO}_{3}$. The mixture of sediment and solution is delivered into a centrifugation separation system through which the solution will be recycled for further absorption, and the sediment is transported and stored in storage tanks.

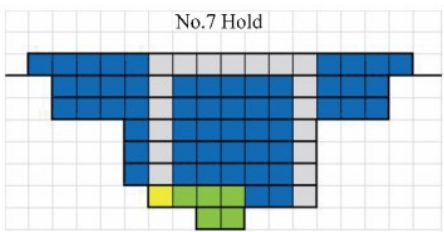

Fig. 5 Arrangement of absorption, solidification processes and storage tanks on a container ship

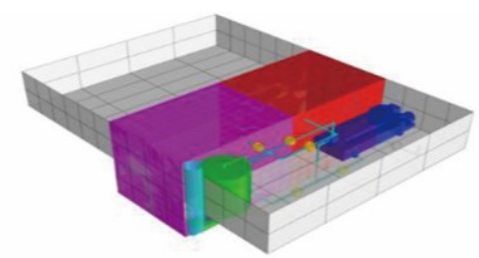

Fig. 6 CAD drawing of carbon absorption and solidification system in working places of the No. 7 hold

\section{Conclusion and recommendations}

This paper presents general and comprehensive reviews on $\mathrm{CO}_{2}$ emission reduction methods, namely, energy efficiency improvement and $\mathrm{CO}_{2}$ capture. The review introduces the methods and presents some technologies and projects. A summary of current $\mathrm{CO}_{2}$ emission reduction technologies and projects indicates that many efforts have been made to mitigate global warming. Energy efficiency improvement and $\mathrm{CO}_{2}$ capture methods can reduce $\mathrm{CO}_{2}$ emissions into the atmosphere. However, CCS is not as popular as energy efficiency improvement for maritime shipping activities. The application of CCS on ships has many constraints, such as high energy, material, and space requirements. Fortunately, two case studies from one maritime CCS research project
Commented [p3]: Please list it in "References" or delete it. Commented [HW4R3]: It is listed in the reference. The second last one.

Commented [p5]: Please list it in "References" or delete it. Please change "the physics hyper textbook" to authors" names.

Commented [HW6R5]: Changed 
indicates and provides the economic feasibility and a practical installation guide for CCS on ships. Therefore, although $\mathrm{CCS}$ is a feasible $\mathrm{CO}_{2}$ emission reduction method, the development of practical onboard CCS applications still has a long way to go.

\section{References}

Barthelemy H, Bourdeaud'huy D, Jolivet J-L, Kohl U, Krinninger K, Teasdale D, Webb A, Williams S, 2010. Safe handling of liquid carbon dioxide containers that have lost pressure. Globally harmonised document, IGC Doc 164/10/E, European Industrial Gases Association (EIGA) Aisbl, Brussels.

Boden TA, Marland G, Andres RJ, 2010. Global, regional, and national fossil-fuel $\mathrm{CO}_{2}$ emissions. Carbon Dioxide Information Analysis Centre, Oak Ridge National Laboratory, U.S. Department of Energy, Oak Ridge.

DOI: 10.3334/CDIAC/00001_V2010

DNV GL and PSE, 2013. Report on ship carbon capture \& storage, Det Norske Veritas, Oslo and London, Available from https://www.psenterprise.com/news/news-press-releases-dnvpse-ccs-report [Accessed on Oct. 16, 2016]

Glenn E, 1998. The Physics Hypertextbook: http://physics.info/heat-latent/. [Accessed on Dec. 12, 2013]

Global CCS Institute, 2012. The Global Status of CCS: 2012. Global CCS Institute, Canberra, Australia. Available from http://decarboni.se/sites/default/files/publications/47936/globalstatus-ccs-2012.pdf [Accessed on Sep. 9, 2016]

Gorgon Australia, 2015. Carbon dioxide injection project. Chevron Project. Available from http://www.chevronaustralia.com/docs/ default-source/default-document-library/fact-sheet-gorgon-c02injection-project.pdf?sfvrsn $=8$ [Accessed on Oct. 16, 2016]

Houghton JT, 2004. Greenhouse gases. In: Global warming: The complete briefing, Cambridge University Press.

IMO, 2011. IMO train the trainer (TTT) course on energy efficient ship operation. International Maritime Organisation, London. Available from http://www.imo.org/en/OurWork/Environment/ PollutionPrevention/AirPollution/Documents/Air\%20pollution/ M2\%20EE\%20regulations\%20and\%20guidelines\%20final.pdf [Accessed on Oct. 18, 2016]

IMO, 2014. Third IMO GHG study 2014. Micropress Printers, Suffolk.

International Chamber of Shipping, 2014. Shipping, world trade and the reduction of $\mathrm{CO}_{2}$ emissions. International Chamber of Shipping (ICS), London.

MAN Diesel \& Turbo, 2014. Improved efficiency and reduced $\mathrm{CO}_{2}$. MAN Diesel \& Turbo, Available from http://marine.man.eu/ docs/librariesprovider6/technical-papers/5510-006801ppr low12553af0bf5969569b45ff0400499204.pdf?sfvrsn=8 [Accessed on Oct. 18, 2016]

Melzer LS, Midland TX, 2012. Carbon dioxide enhanced oil recovery $\left(\mathrm{CO}_{2} \mathrm{EOR}\right)$ : Factors involved in adding carbon capture, utilization and storage (CCUS) to enhanced oil recovery. The National Enhanced Oil Recovery Initiative, Center for Climate and Energy Solutions, 1-17.

MEPC, 2011. MARPOL Annex VI, Chapter IV, http://www.imo.org/en/OurWork/Environment/PollutionPrevent ion/AirPollution/Documents/Air\%20pollution/M2\%20EE\%20r egulations $\% 20$ and $\% 20$ guidelines $\% 20$ final.pdf,

Metz B, Davidson O, de Coninck HC, Loos M, Meyer LA, 2007. IPCC special report on carbon dioxide capture and storage. Prepared by Working Group III of the Intergovernmental Panel on Climate Change, Cambridge University Press.

National Geographic, 1999. The greenhouse effect. Available from http://environment.nationalgeographic.com/environment/global -warming/gw-overview-interactive/ [Accessed on Sep. 9, 2016]

SaskPower, 2014. Boundary dam integrated carbon capture and storage demonstration project. SaskPower CCS, Regina. Available from http://www.saskpower.com/wp-content/uploads/ clean coal information sheet pdf [Accessed on Oct. 18, 2016]

Shao W, Zhou PL, Thong SK, 2012. Development of a novel forward dynamic programming method for weather routing. Journal of Marine Science and Technology, 17(2), 239-251.

DOI: $10.1007 / \mathrm{s} 00773-011-0152-\mathrm{z}$

Stern D, 2011. Global trends in carbon and sulfur emissions Available from http://stochastictrend.blogspot.co.uk/2011/03/ global-trends-in-carbon-and-sulfur.html [Accessed on Sep. 9, 2016]

U.S. Department of Energy, 2013. FutureGen 2.0 Project, Final Environmental Impact Statement, Available from http:// energy.gov/sites/prod/files/2013/10/f4/EIS-0460-FEISVolume_II_Part_1-2013.pdf [Accessed on Oct. 16, 2016]

Wang HB, Zhou PL, Wang ZC, 2016. Experimental and numerical analysis on controllable factors of $\mathrm{CO}_{2}$ absorption efficiency of carbon solidification system. Ocean Engineering, 113, 133-143. DOI: $10.1016 /$ j.oceaneng.2015.12.036

Wischnewski B, 2006. Peace software. Available from http://www. peacesoftware.de/einigewerte/co2 e.html [Accessed on Sep.12, 2013]

Zhou PL, Wang HB, 2014. Carbon capture and storageSolidification and storage of carbon dioxide captured on ships. Ocean Engineering, 91, 172-180.

DOI: $10.1016 /$ j.oceaneng.2014.09.006
Commented [p7]: Please index references by yellow in the text, or delete them.

Commented [HW8R7]: added 